\title{
ANÁLISE DA VALUE RELEVANCE DA DEMONSTRAÇÃO DO VALOR ADICIONADO NOS NÍVEIS DIFERENCIADOS DE GOVERNANÇA CORPORATIVA DA BM\&FBOVESPA
}

\author{
VALUE RELEVANCE ANALYSIS OF THE VALUE ADDED STATEMENT IN THE \\ VARIOUS CORPORATE GOVERNANCE LEVELS AT BM\&FBOVESPA
}

\author{
ALYNE ALVES SANTOS \\ Universidade Federal de Uberlândia. Endereço: Av. João Naves de Ávila, \\ 2121, 1F215 | Santa Mônica | 38400-902 | Uberlândia/MG | Brasil. \\ (D) http://orcid.org/0000-0002-2476-7383 \\ alyne.alves09@gmail.com
}

\section{REINER ALVES BOTINHA}

Universidade Federal de Uberlândia. Endereço: Av. João Naves de Ávila, 2121, 1F249 | Santa Mônica | 38400-902 | Uberlândia/MG | Brasil. (D)ttp://orcid.org/0000-0001-9968-6484

reiner.botinha@gmail.com

\section{SIRLEI LEMES}

Universidade Federal de Uberlândia. Endereço: Av. João Naves de Ávila, 2121, 1F255 | Santa Mônica | 38400-902 | Uberlândia/MG | Brasil. (D) http://orcid.org/0000-0003-3334-4240

sirlemes@uol.com.br

\section{RESUMO}

O objetivo deste estudo foi identificar se o conteúdo informacional da Demonstração do Valor Adicionado (DVA) é relevante para os investidores. A amostra foi composta por empresas brasileiras pertencentes ao Índice de Ações com Governança Corporativa Diferenciada (IGCX) da BM\&FBovespa, atual Brasil, Bolsa, Balcão (B3), no período de 2011 a 2015. Para o alcance do objetivo, foi utilizada a técnica de regressão linear múltipla. A amostra da pesquisa constituiu-se de 155 empresas e 714 observações. Os resultados apontam que a variável "valor adicionado líquido para distribuição", ao nível de significância estatística de 5\%, é relevante para o mercado acionário nos níveis diferenciados de governança corporativa, porém com baixo poder explicativo. Todavia, quando as variáveis de controle são adicionadas na regressão, observa-se que o lucro por ação apresenta mais poder explicativo em relação ao valor adicionado líquido. Esses resultados apontaram que o total de riqueza líquida obtida pela empresa (construída por ela e recebida em transferência por outras entidades) pode ser relevante para os usuários das informações contábeis, embora o lucro por ação tenha sido o indicador mais relevante. Evidenciou-se que, em linhas gerais, há preocupação quanto à divulgação da informação sobre a riqueza gerada pela entidade, sinalizando que o conteúdo da DVA conduz à maior transparência das entidades e, consequentemente, é capaz de influenciar as decisões dos investidores, mas tem baixo teor de coeficiente em relação às demais variáveis do estudo. 
Palavras-chave: Relevância Informacional. DVA. Governança Corporativa. Value relevance.

\begin{abstract}
The objective of the present study was identifying whether the informational content of the Value Added Statement (VAS) is relevant for investors. The sample entailed Brazilian companies belonging to the Special Corporate Governance Stock Index (IGCX) of BM\&FBovespa, currently known as Brazil, Stock Exchange and Over-the-Counter Market (B3), in the period from 2011 to 2015. In order to achieve the objective, we employed multiple linear regression. 155 companies and 714 observations entailed the survey sample. The results indicate that the variable "net value added for distribution", at the statistical significance level of 5\%, is relevant for the stock market at the various levels of corporate governance, however, it displays low explanatory power. Nevertheless, when the control variables are added in the regression, we may observe that earnings per share have more explanatory power in relation to net value added. These results indicated that the total net wealth obtained by the company (built by it and received in transfer from other entities) may be relevant to the users of the accounting information, although earnings per share were the most relevant indicator. We could not that, in general terms, there is concern about the information disclosure on the wealth generated by the entity, indicating that the content of the VAS leads to greater transparency of the entities and, consequently, is capable of influencing the decisions of the investors, but it presents a low coefficient content in relation to the other variables of the study.
\end{abstract}

Keywords: Informational Relevance. VAS. Corporate governance. Value relevance.

\title{
1 INTRODUÇÃO
}

No contexto de convergência contábil, com o estabelecimento dos padrões contábeis internacionais, a busca por informações que garantam auxílio e confiabilidade na tomada de decisão tem se tornado cada vez mais essencial aos usuários das informações contábeis. Cosenza (2003) destaca que, com a evolução da atividade comercial, surgiram novos usuários, ressaltando a relevância destes como importantes contribuintes da economia, que se interessam pelas informações da empresa e que se relacionam com o ambiente em que estão inseridos.

Perante o interesse em apresentar aos usuários melhores informações, sobretudo aos investidores, de acordo com Luca, Cunha, Ribeiro e Oliveira (2009), a Demonstração do Valor Adicionado (DVA) surgiu para satisfazer a precisão dos usuários das demonstrações contábeis sobre o valor da riqueza gerada pela empresa e sua distribuição aos entes que contribuíram para a criação desse valor e que são beneficiados por ele.

Em poucos países a legislação exige a publicação da DVA, porém o International Accounting Standards Board (IASB) incentiva sua divulgação (Luca et al., 2009). Anos anteriores à regulamentação dessa demonstração no Brasil, algumas entidades evidenciavam a DVA voluntariamente, por influência do aumento da conscientização das pessoas, que solicitavam informações adicionais às financeiras (Almeida, \& Coutinho e Silva, 2014).

Com o incremento da divulgação da DVA, alguns estudos têm sido desenvolvidos com a finalidade de analisar a relevância dessa demonstração no Brasil e no exterior (Arruda, Garcia, \& Lucena, 2015; Barros, Catapan, Scherer, \& Isidoro, 2013; Cosenza, 2003; Crippa, \& Coelho, 2012; Machado, Macedo, \& Machado, 2015; Stanzani, Fregonesi, \& Nakao, 2016; Yogesha, \& Mahadevapa, 2014). No geral, esses estudos buscam verificar se de fato a elaboração, o aprimoramento e a apresentação dessa demonstração contábil são relevantes e geram benefícios que superam os custos de sua elaboração.

Quando se fala em relevância, remete-se às pesquisas que tratam de value relevance. Barros et al. (2013) usam o termo como sinônimo de conteúdo informacional. Nesse mesmo 
sentido, para Machado et al. (2015), esse conceito se refere às pesquisas que investigam a relevância e o efeito das informações contábeis no mercado de capitais, mais precisamente, no preço das ações. Nesta pesquisa, ao investigar o value relevance da DVA, o foco é o efeito das informações da DVA no preço das ações. Portanto, o objetivo consistiu em identificar se seu conteúdo apresenta valor relevante para os investidores.

A partir das exigências do mercado de capitais brasileiro e da necessidade de melhorar a relação com os investidores, criaram-se níveis diferenciados de governança corporativa com a intenção de aumentar a transparência aos investidores e, por conseguinte, proporcionar a valorização dessas companhias (Almeida et al., 2014).

Destaca-se que, à medida que as empresas se esforçam para aperfeiçoar a relação com os investidores, ocorre a valorização dos seus ativos nos níveis de governança corporativa (Malacrida, \& Yamamoto, 2006). Considerando a importância supostamente atribuída aos investidores pelas empresas pertencentes aos níveis diferenciados de governança corporativa da BM\&FBovespa (atual B3), tais empresas compuseram a amostra da pesquisa.

As pesquisas de Barros et al. (2013) e Machado et al. (2015) evidenciaram uma associação entre o valor adicionado líquido e o preço de mercado das ações das companhias brasileiras. Martins, Machado e Callado (2014) não encontraram relevância no conteúdo informacional da DVA ao analisar se ela conseguia explicar o retorno das ações no mercado acionário. Assim, observa-se uma lacuna na literatura quanto à relevância dessa demonstração para o mercado de capitais e a uma dualidade de resultados; é para essa lacuna que esse estudo busca contribuições.

Esta pesquisa também avança em relação aos estudos anteriores, ao analisar não apenas a relação entre o valor adicionado líquido e o preço das ações, mas também a value relevance do valor adicionado, distribuído em forma de remuneração de capital próprio. Além disso, testam-se outras variáveis explicativas consideradas pela literatura, bem como períodos mais recentes em relação às pesquisas anteriores.

A pesquisa justifica-se pela necessidade de transparência das informações organizacionais, bem como pela contribuição das informações contidas na DVA à sociedade e aos agentes beneficiadores da informação contábil, visto que a bibliografia existente ainda deixa em aberto questões quanto à relevância da DVA. Pesquisas correlatas foram desenvolvidas anteriormente (Barros et al., 2013; Martins et al., 2014; Machado et al., 2015) e contribuíram com a literatura.

Com o resultado desta pesquisa, espera-se contribuir com a literatura já existente sobre a relevância da DVA, desde a determinação de sua obrigatoriedade de divulgação, em conjunto com as demonstrações financeiras no mercado acionário brasileiro. Como contribuição prática, espera-se conscientizar os usuários das demonstrações contábeis sobre o conteúdo informacional que ela carrega e que pode auxiliar na tomada de decisão.

\section{REVISÃO DA LITERATURA}

\subsection{Value relevance da informação contábil}

A informação contábil é apontada como uma ferramenta decisória na tomada de decisões aos seus usuários, até mesmo para os que analisam os investimentos no mercado acionário (Marques, Santos, \& Lemes, 2014). No entanto, para tal, é necessário que ela seja relevante e represente fielmente os dados apresentados (Fé, 2013).

De acordo com Rezende, Batistella, Dalmácio e Brito (2008), pesquisas voltadas para o value relevance têm sido desenvolvidas no ambiente acadêmico, tomando como referência o lucro ou patrimônio líquido da entidade. As pesquisas normalmente são efetuadas com o auxílio de ferramentas estatísticas, notadamente com o uso da análise de regressão linear, na qual se 
atribui uma variável dependente, relativa ao preço das ações, e como variável independente, as demais relacionadas à contabilidade (Martins et al., 2014).

Segundo Machado et al. (2015), estudos relacionados à value relevance utilizam o mercado de capitais como cobaia para testes de associação entre a relevância da informação contábil e a variação de valores do ativo, ou seja, busca-se nos estudos quantificar a utilidade das informações contábeis para os investidores com a finalidade de formação do preço das ações (Macedo, Romano, \& Silva, 2014).

Rodrigues, Elias e Campos (2014) evidenciaram a existência da relevância do conteúdo informacional das demonstrações contábeis aos investidores. Segundo os autores, o mercado de capitais responde as informações contábeis das demonstrações, associadas à tempestividade em que são repassadas a seus usuários.

$\mathrm{O}$ aumento de pesquisas que associam a evidenciação das demonstrações financeiras com a reação do mercado acionário trouxe como consequência a inclusão de novas variáveis para explicar a relevância da informação contábil; dentre essas, destacam-se as práticas de governança corporativa (Lima, 2010). O autor complementa que as demonstrações financeiras contêm informações que afetam o preço das ações e chamam atenção dos investidores, se forem variáveis relacionadas à governança corporativa.

Cahan, Emanuel e Sun (2009) investigaram a relevância de variáveis relacionadas ao lucro das empresas. Para os autores, essa relevância depende da qualidade dos ganhos relacionados à transparência e proteção dos investidores. Os autores auferiram que a relevância da informação contábil tem forte relação com os mecanismos de proteção aos investidores, dentre os quais pode-se citar, no Brasil, os níveis diferenciados de governança corporativa.

Em estudo realizado sobre a relação entre a governança corporativa e a value relevance das informações contábeis na Austrália, foi constatado que empresas com fortes práticas de governança corporativa melhoram a value relevance e conseguem influenciar o preço das ações das companhias (Habib, \& Azim, 2008).

Na mesma linha de pesquisa de Habib e Azim (2008), Lopes (2009) evidenciou a relação existente entre índice de governança corporativa e value relevance em empresas brasileiras, apontando que boas práticas de governança corporativa resultam em maior relevância do lucro. Observa-se que a value relevance da informação contábil está relacionada a diversos fatores ligados à qualidade da informação contábil, sendo um deles, a capacidade para influenciar a decisão dos investidores. Nesta pesquisa, foi avaliada a relevância da DVA e, dessa forma, na próxima seção essa demonstração é discutida.

\subsection{A Demonstração do Valor Adicionado}

De acordo com Luca et al. (2009), a DVA vem sendo incentivada no Brasil desde a década de 1980, sob o argumento de que a criação e distribuição da riqueza gerada pela entidade seriam evidenciadas. A DVA passou a ser explorada em 1970, em diversos países da Europa, porém, o Reino Unido destacou-se em relação aos demais pela notoriedade ao incentivar a elaboração da DVA por meio do Comitê de Normas Contábeis em 1975 e, como consequência, a cada ano o número de empresas que divulgavam esse relatório de forma voluntária aumentou (Machado et al., 2015).

Com a disseminação da DVA, a demonstração passou a integrar os relatórios anuais de empresas alemãs, belgas, holandesas e norueguesas. Todavia, sob a ótica das Normas Internacionais de Contabilidade - International Financial Reporting Standards (IFRS) -, não há a obrigatoriedade de publicação dessa demonstração, sendo que o IASB apenas incentiva sua evidenciação, apesar de não haver uma norma IFRS que oriente a elaboração da DVA (Luca et al., 2009). Entretanto, segundo Oshiro (2003), países europeus interessados na divulgação da partilha da riqueza gerada pelas empresas e motivados por recomendações de organismos internacionais já determinaram a publicação dessa demonstração, de forma similar ao que ocorreu no Brasil, em que normas locais tornaram a DVA obrigatória. 
Haller e Van Staden (2014) apontam que o conceito do valor adicionado, evidenciado na DVA desde o século XVIII, vem sendo utilizado como medida de desempenho nos Estados Unidos e que ela se constitui em um importante instrumento de comunicação de resultados aos seus diversos stakeholders, de forma eficiente e eficaz.

Com o advento da Lei n. 11.638, de 28 de dezembro de 2007, a evidenciação da DVA no Brasil passou a ser obrigatória para as empresas denominadas Sociedades Anônimas (S/A), enquanto nas demais sociedades sua publicação é facultativa. Contudo, dado o conteúdo informacional contido na referida demonstração, recomenda-se que todas as empresas a adotem (Azevedo, 2009).

De acordo com o Comitê de Pronunciamentos Contábeis (CPC), no CPC 09, a riqueza gerada pela empresa deve ser distribuída, no mínimo, entre os seguintes grupos: i) pessoal e encargos; ii) impostos, taxas e contribuições; iii) remuneração de capitais de terceiros (juros, aluguéis e outros); e iv) remuneração de capitais próprios (juros sobre o capital próprio e dividendos e lucros retidos ou prejuízo do exercício). Os grupos em que se divide a DVA estão em linha com a citação de Oliveira e Coelho (2014), segundo os quais a DVA demonstra a riqueza gerada pela empresa em seu âmbito econômico e deve propiciar a seus usuários conhecimento sobre a distribuição de tais riquezas.

A necessidade de informações mais completas fundamentou a importância atribuída à DVA no contexto da convergência contábil, visto que ela não deve ser confundida com a Demonstração do Resultado do Exercício (DRE). Cunha, Ribeiro e Santos (2005) salientam que a DRE restringe a capacidade da empresa em gerar lucros apenas aos acionistas, sem considerar os fatores econômicos que contribuíram para a geração de riqueza da entidade. Van Staden (2000) faz um contraponto, afirmando que a DVA apresenta pouca inovação no que tange às informações já contidas na DRE, entretanto, aquela apresenta a informação de forma mais clara e concisa.

Cosenza (2003) salienta que o propósito da DVA não é substituir a DRE, mas complementá-la, visto que sua estrutura conceitual permite o entendimento dos benefícios gerados e seus impactos no resultado da empresa e de quem participa dele, particularmente os empregados, credores financeiros e governo. Na mesma linha, Britto, Silva, Diniz e Miranda (2005) afirmam que a DVA apresenta, de forma objetiva e compreensível, a partilha da riqueza gerada pela empresa a cada um de seus colaboradores, tornando-se essencial para atender a carência de informações que não estão contidas em outras demonstrações contábeis.

Arruda et al. (2015) ampliam a abrangência da DVA ao afirmar que, além de demonstrar a geração e distribuição de riqueza, ela proporciona o conhecimento de informações de natureza econômica e social e oferece a possibilidade de melhor avaliação das atividades da entidade dentro da sociedade na qual está inserida No cenário internacional, Mook (2007) destaca a contribuição dessa demonstração à contabilidade, pois une, em um único relatório, tópicos que eram ocultos nas demais demonstrações e que auxiliam na análise de desempenho organizacional graças ao seu rico conteúdo informacional. Yogesha e Mahadevapa (2014) ressaltam que a DVA evidencia resultados para um grupo maior de stakeholders em relação às demais demonstrações e seus componentes servem para medir o desempenho econômico das entidades.

Os resultados das pesquisas, como citado, ainda deixam em aberto questões relativas à relevância e importância informacional da DVA. Assim, Kroetz e Neumann (2008) destacam a necessidade de se ampliar a proposta de apresentação dessa demonstração para melhor explorar o potencial da DVA.

\subsection{Evidências empíricas anteriores sobre a value relevance da DVA}

Estudos anteriores com objetivos semelhantes foram desenvolvidos a fim de contribuir para a construção da literatura existente e evidenciar a value relevance da DVA no conjunto das demonstrações financeiras. Barros et al. (2013) evidenciaram a relevância da DVA, associando o preço das ações com o valor adicionado líquido a distribuir, de 2000 a 2009, para uma amostra 
de 642 empresas listadas na bolsa de valores. Os autores apontaram que o conteúdo informacional contido na DVA é relevante para os diferentes níveis de governança corporativa.

Stanzani et al. (2016) verificaram a relevância da DVA para uma amostra de 62 empresas listadas na BM\&FBovespa, de 2010 a 2012, e confirmaram a relevância dessa demonstração para explanar a variação no retorno das ações e para o mercado acionário. Arruda et al. (2015) evidenciaram que as divisões constantes na DVA pouco influenciam o retorno das ações em horizontes de tempos diferentes. Para analisar o retorno das ações, eles observaram três janelas de eventos: curta (três dias antes e após a divulgação das demonstrações), média (sete dias antes e após) e longa (15 dias antes e após). Os autores evidenciaram que os juros sobre o capital próprio possuem relação negativa em um período considerado curto (de três dias) - ou seja, nesse período, os valores evidenciados nessa categoria afetam negativamente o retorno das ações.

Em outro estudo, Machado et al. (2015) apontaram a relevância da DVA na explicação do retorno das ações e que a riqueza criada por ação representa melhor a capacidade de explicar esse retorno, pois os usuários esperam que a empresa crie riquezas que garantam a acessibilidade futura e não só a remuneração do capital próprio.

Crippa e Coelho (2012), em estudo similar ao de Machado et al. (2015), utilizando como amostra empresas listadas na BM\&FBovespa, chegaram à conclusão de que além da DVA ser relevante, ela pode apresentar informações quanto à conduta da empresa diante da governança corporativa e dos interesses de usuários dessa informação.

Scherer (2006) também constatou a relevância do valor adicionado líquido para a distribuição em empresas listadas na BM\&FBovespa. Em análise adicional, ao separar as empresas da amostra entre aquelas que pertenciam a níveis diferenciados de governança corporativa daquelas não pertencentes, ele relatou a relevância do valor adicionado, demonstrado na DVA, em empresas pertencentes, o que, segundo o autor, é justificado pela necessidade dos investidores de informações complementares que fundamentem suas decisões. A Tabela 1 reporta os resultados de pesquisas sobre value relevance, bem como as hipóteses testadas neste estudo.

Tabela 1

\section{Estado da arte e respectivas hipóteses}

\begin{tabular}{l|l|l}
\hline $\begin{array}{c}\text { Autores } \\
\text { e ano }\end{array}$ & \multicolumn{1}{c|}{ Resultados } & \multicolumn{1}{c}{ Hipótese } \\
\hline $\begin{array}{l}\text { Machado } \\
\text { et al. } \\
(2015)\end{array}$ & $\begin{array}{l}\text { A DVA possui conteúdo informacional relevante, } \\
\text { pois explica a variação no preço das ações das } \\
\text { empresas. A relação entre a riqueza criada por ação } \\
\text { (RCPA) e o preço mostrou-se significativa, mesmo } \\
\text { com a inclusão das variáveis patrimônio líquido por } \\
\text { ação (PLPA) e lucro líquido por ação (LLPA). }\end{array}$ & $\begin{array}{l}\text { H1: Empresas com poder de distribuição } \\
\text { maior influenciam o preço da ação da } \\
\text { companhia. }\end{array}$ \\
\hline $\begin{array}{l}\text { Barros } \text { et } \\
\text { al. } \\
(2013)\end{array}$ & $\begin{array}{l}\text { O valor adicionado líquido para distribuição é } \\
\text { relevante para o investidor. } \\
\text { O patrimônio líquido mostrou-se não relevante para } \\
\text { o mercado. }\end{array}$ & $\begin{array}{l}\text { H2: Empresas que geram valor a seus } \\
\text { acionistas, influenciam o preço da ação da } \\
\text { companhia. }\end{array}$ \\
$\begin{array}{l}\text { H3: Empresas que se concentram em criar } \\
\text { valor patrimonial, influenciam o preço da } \\
\text { ação da companhia. }\end{array}$ \\
$\begin{array}{l}\text { Crippa e e } \\
\text { Coelho } \\
(2012)\end{array}$ & $\begin{array}{l}\text { O mercado não considera a informação da riqueza } \\
\text { destinada aos acionistas com a mesma relevância } \\
\text { com que aprecia a capacidade de produção de } \\
\text { riqueza das empresas, sendo o valor da firma mais } \\
\text { associado à riqueza gerada, do que à forma como a } \\
\text { riqueza é distribuída entre os stakeholders. } \\
\text { O tamanho da empresa apresentou associação com o } \\
\text { retorno das ações, enquanto o nível de } \\
\text { endividamento das empresas não apresentou } \\
\text { influencia o preço da ação da companhia. }\end{array}$ \\
$\begin{array}{l}\text { H5: O endividamento da empresa influencia o } \\
\text { preço da ação da companhia. } \\
\text { H6: O ativo total da empresa influencia o } \\
\text { preço da ação da companhia. }\end{array}$ \\
\hline
\end{tabular}




\begin{tabular}{|c|c|c|}
\hline & significância estatística. & \\
\hline $\begin{array}{l}\text { Klapper } \\
\text { e Love } \\
(2002)\end{array}$ & $\begin{array}{l}\text { A governança está correlacionada à extensão da } \\
\text { informação assimétrica e às imperfeições de } \\
\text { contratação que as empresas enfrentam. Uma melhor } \\
\text { governança corporativa está altamente } \\
\text { correlacionada ao melhor desempenho operacional e } \\
\text { à avaliação de mercado. } \\
\text { Empresas com American Depositary Receipt (ADR) } \\
\text { possuem melhores práticas de governança } \\
\text { corporativa e, assim, possuem melhores resultados } \\
\text { no mercado de capitais. }\end{array}$ & $\begin{array}{l}\text { H8: O nível de governança corporativa no } \\
\text { qual a empresa está listada influencia o preço } \\
\text { da ação da companhia. } \\
\mathrm{H}_{9} \text { : O fato de a empresa emitir ações no } \\
\text { mercado de ações norte-americano influencia } \\
\text { o preço da ação da companhia. }\end{array}$ \\
\hline
\end{tabular}

Fonte: elaborado pelos autores.

No próximo tópico, são apresentados os aspectos metodológicos que embasam a pesquisa, no que tange aos objetivos, aos procedimentos técnicos, à abordagem do problema e aos instrumentos de coleta de dados.

\section{ASPECTOS METODOLÓGICOS}

A amostra da pesquisa é composta por empresas pertencentes ao Índice de Ações com Governança Corporativa Diferenciada (IGCX) da Brasil, Bolsa, Balcão (B3), listadas no índice em 14 de novembro de 2016 e com os dados extraídos no período de 2011 a 2015. Sobretudo, compõem a amostra empresas listadas nos níveis de governança corporativa de nível 1, nível 2 e Novo Mercado. Ao todo, 155 empresas (total de 714 observações) foram investigadas. De um total inicial de 180 empresas, 15 foram excluídas por estarem listadas em duplicidade, em função de negociarem diferentes tipos de ações, e dez foram excluídas por indisponibilidade de algumas informações na DVA.

Para evidenciar o poder explicativo da DVA e sua associação com o preço das ações da B3, as hipóteses foram testadas por meio da técnica de regressão linear múltipla por mínimos quadrados ordinários (OLS), observando os pressupostos básicos propostos por Fávero, Belfiore, Takamatsu e Suzart (2014). Com o propósito de corrigir a normalidade dos dados utilizados no teste de regressão, utilizou-se a técnica de winsorização, bem como o teste Ladder, que aponta a correção necessária para as variáveis quanto à assimetria de distribuição. Identificou-se a necessidade de correção apenas do preço da ação pela raiz quadrada (pa_sqt) e do ativo total pelo logaritmo neperiano (atl). A Tabela 2 lista as variáveis testadas com as respectivas hipóteses e os estudos motivadores da metodologia adotada.

Tabela 2

Variáveis utilizadas na pesquisa

\begin{tabular}{|c|c|c|c|c|}
\hline Variável- Sigla & Hipótese & Fórmula/métrica & Sinal & Estudos motivadores \\
\hline \multirow{2}{*}{$\begin{array}{l}\text { (Dependente) } \\
\text { Preço da ação } \\
(\mathbf{P a})\end{array}$} & & $p a$ & & \multirow{2}{*}{$\begin{array}{l}\text { Barros et al. (2013); } \\
\text { Arruda et al. (2015); } \\
\text { Machado et al. }(2015)\end{array}$} \\
\hline & & $p a(t-1)$ & & \\
\hline \multirow{2}{*}{$\begin{array}{l}\text { (Independentes) } \\
\text { Lucro por ação } \\
\text { (La) }\end{array}$} & \multirow{2}{*}{$\begin{array}{l}\mathrm{H}_{1} \text { : Empresas com poder } \\
\text { de distribuição maior } \\
\text { influenciam o preço da } \\
\text { ação da companhia. }\end{array}$} & la & \multirow[b]{2}{*}{+} & \multirow{2}{*}{$\begin{array}{l}\text { Scherer (2006); } \\
\text { Stanzani et al. (2016); } \\
\text { Machado et al. }(2015)\end{array}$} \\
\hline & & $l a(t-1)$ & & \\
\hline \multirow{2}{*}{$\begin{array}{c}\text { Valor } \\
\text { adicionado } \\
\text { líquido para } \\
\text { distribuição } \\
\text { por ação } \\
\text { (Val_a) } \\
\end{array}$} & \multirow{2}{*}{$\begin{array}{l}\mathrm{H}_{2} \text { : Empresas que geram } \\
\text { valor a seus acionistas } \\
\text { influenciam o preço da } \\
\text { ação da companhia. }\end{array}$} & $v a l \_a$ & \multirow[b]{2}{*}{+} & \multirow{2}{*}{$\begin{array}{l}\text { Barros et al., 2013; } \\
\text { Scherer (2006); Crippa } \\
\text { e Coelho (2012) }\end{array}$} \\
\hline & & $v a l \_a(t-1)$ & & \\
\hline $\begin{array}{c}\text { Valor } \\
\text { patrimonial }\end{array}$ & $\begin{array}{c}\mathrm{H}_{3} \text { : Empresas que se } \\
\text { concentram em criar valor }\end{array}$ & $v p a$ & + & Barros et al. (2013) \\
\hline
\end{tabular}




\begin{tabular}{|c|c|c|c|c|}
\hline por ação (Vpa) & $\begin{array}{l}\text { patrimonial influenciam o } \\
\text { preço da ação da } \\
\text { companhia. }\end{array}$ & $v p a(t-1)$ & & \\
\hline \multirow{2}{*}{$\begin{array}{l}\text { Proporção do } \\
\text { VAD para } \\
\text { capital próprio } \\
\text { (Vatpro) }\end{array}$} & \multirow{2}{*}{$\begin{array}{c}\mathrm{H}_{4}: \mathrm{O} \text { valor distribuído } \\
\text { para capital próprio } \\
\text { influencia o preço da ação } \\
\text { da companhia. }\end{array}$} & vapro & \multirow{2}{*}{+} & \multirow{2}{*}{$\begin{array}{l}\text { Martins et al. }(2014) ; \\
\text { Barros et al. }(2013) \\
\quad \text { Scherer }(2006)\end{array}$} \\
\hline & & vat & & \\
\hline \multirow{2}{*}{$\begin{array}{l}\text { Endividamento } \\
\text { (End) }\end{array}$} & \multirow{2}{*}{$\begin{array}{c}\mathrm{H}_{5}: \mathrm{O} \text { endividamento da } \\
\text { empresa influencia o preço } \\
\text { da ação da companhia. }\end{array}$} & $a t-p l$ & \multirow[b]{2}{*}{-} & \multirow{2}{*}{$\begin{array}{l}\text { Crippa e Coelho } \\
\text { (2012) }\end{array}$} \\
\hline & & at & & \\
\hline Ativo total (At) & $\begin{array}{c}\mathrm{H}_{6}: \mathrm{O} \text { ativo total da } \\
\text { empresa influencia o preço } \\
\text { da ação da companhia. }\end{array}$ & $\begin{array}{l}\text { Logaritmo neperiano do ativo } \\
\text { total da empresa. }\end{array}$ & + & $\begin{array}{l}\text { Crippa e Coelho } \\
\text { (2012) }\end{array}$ \\
\hline Setor (Set) & $\begin{array}{c}\mathrm{H}_{7}: \mathrm{O} \text { setor de } \\
\text { classificação da empresa } \\
\text { influencia o preço da ação } \\
\text { da companhia. }\end{array}$ & \begin{tabular}{|lrl} 
Dummies setores: $1-$ & Bens \\
industriais; $2-$ & Consumo \\
cíclico; $3-$ & Consumo não \\
cíclico; 4 - Financeiro e outros; \\
$5-$ Materiais básicos; 6 & - \\
Petróleo, & gás & e \\
biocombustíveis; 7 - Saúde; & 8 \\
- Tecnologia da informação; 9 \\
- Telecomunicações; 10 - \\
Utilidade pública.
\end{tabular} & + & \\
\hline $\begin{array}{l}\text { Governança } \\
\text { corporativa } \\
\text { (Gcorp) }\end{array}$ & $\begin{array}{l}\mathrm{H}_{8}: \text { O nível de governança } \\
\text { corporativa no qual a } \\
\text { empresa está listada } \\
\text { influencia o preço da ação } \\
\text { da companhia. }\end{array}$ & $\begin{array}{l}\text { Dummies governança } \\
\text { corporativa: } 1 \text { - Nível } 1 ; 2- \\
\text { Nível } 2 ; 3 \text { - Novo Mercado. }\end{array}$ & + & Klapper e Love (2002) \\
\hline ADR & $\begin{array}{c}\mathrm{H}_{9}: \mathrm{O} \text { fato de a empresa } \\
\text { emitir ações no mercado } \\
\text { de ações norte-americano } \\
\text { influencia o preço da ação } \\
\text { da companhia. }\end{array}$ & $\begin{array}{l}\text { Dummy 0: a empresa não emite } \\
\text { ações nos Estados Unidos; } \\
\text { Dummy 1: a empresa emite } \\
\text { ações nos Estados Unidos. }\end{array}$ & + & Klapper e Love (2002) \\
\hline
\end{tabular}

Fonte: adaptado de Barros et al. (2013) para as variáveis utilizadas na pesquisa.

Embora outras pesquisas não tenham testado a relação incluindo a classificação setorial como variável de controle, nesta pesquisa isso foi feito com o intuito de verificar se o setor interfere no desempenho da empresa. A Equação 1 exprime o modelo de regressão que foi testado neste estudo.

Equação 1

$\mathrm{Pa}_{\mathrm{ij}}=\beta_{0}+\beta_{1} \mathrm{La}_{\mathrm{ij}}+\beta_{2} \mathrm{Val}_{-} \mathrm{a}_{\mathrm{ij}}+\beta_{3} \mathrm{Vpa}_{\mathrm{ij}}+\beta_{4} \mathrm{Vatpro}_{\mathrm{ij}}-\beta_{5}$ End $_{\mathrm{ij}}+\beta_{6} \mathrm{At}_{\mathrm{ij}}+\beta_{7} \mathrm{i} \cdot \mathrm{Set}_{\mathrm{ij}}+\beta_{8} \mathrm{i} \cdot \mathrm{Gcorp}_{\mathrm{ij}}+\beta_{9} \mathrm{i} . \mathrm{Ano}+\beta_{10} \mathrm{Adr}_{\mathrm{ij}}+\varepsilon$ (1)

O tópico a seguir relata os resultados da pesquisa e suas principais discussões, sendo os resultados apresentados por meio da estatística descritiva e por meio do modelo de regressão mencionado.

\section{ANÁLISE DOS RESULTADOS}

\subsection{Estatísticas descritivas}

Na Tabela 3 consta a estatística descritiva das variáveis quantitativas da pesquisa. 
Tabela 3

Estatística descritiva das variáveis quantitativas

\begin{tabular}{ccccccc}
\hline Variáveis & Obs & Média & Mediana & Desvio Padrão & Mínimo & Máximo \\
\hline Pa & 715 & 0,95 & 0,93 & 0,38 & 0,17 & 1,97 \\
La & 775 & $(0,84)$ & 0,64 & 10,98 & $(90,15)$ & 14,79 \\
Val_a & 715 & $245.443,90$ & $82.940,40$ & $459.966,80$ & $(18.917,33)$ & $2.426 .104,00$ \\
Vpa & 769 & 18,15 & 9,16 & 34,45 & $(0,30)$ & 244,50 \\
Vatpro & 774 & 0,09 & 0,15 & 0,69 & $(4,40)$ & 2,19 \\
End & 769 & 2,48 & 1,43 & 3,06 & $(3,28)$ & 16,87 \\
At & 769 & 32.300 .000 & 4.834 .415 & 138.000 .000 & 135.299 & 1.030 .000 .000 \\
\hline
\end{tabular}

Nota. $\mathrm{Pa}=$ Preço da ação; La = Lucro por ação; Val_a = Valor Adicionado Líquido para distribuição por ação; VPA = Valor patrimonial por ação; Vatpro = Proporção do valor adicionado distribuído para capital próprio; End = Endividamento; At = Ativo total. Fonte: elaborado pelos autores.

As variáveis que apresentaram maior média e mediana (Tabela 3) foram o valor adicionado líquido a distribuir por ação e o valor patrimonial por ação, porém ressalta-se o elevado valor do desvio padrão da variável valor adicionado líquido a distribuir por ação. No que tange aos mínimos e máximos, é importante ressaltar que, ao dividir o preço da ação pelo preço da ação anterior, reduz-se o efeito da escala das variáveis. Assim, o menor valor (mínimo) do preço da ação é 0,17 e o maior (máximo) é 1,97.

Cabe salientar que as diferentes observações expostas na Tabela 3 são devido à presença de dados omissos - os que não estavam disponíveis para determinada variável e indivíduo. Assim, algumas empresas podem ter apresentado valor patrimonial por ação (VPA) e não ter evidenciado o valor da ação, resultando em uma quantidade maior de observações para VPA. Na Tabela 4 encontra-se a frequência relativa das variáveis qualitativas do estudo.

Tabela 4

Estatística descritiva das variáveis qualitativas

\begin{tabular}{|c|c|c|c|c|}
\hline & & $\begin{array}{c}\text { Freq. } \\
\mathrm{N}=775\end{array}$ & Freq. Relativa & Freq. Acumul. \\
\hline \multirow[t]{10}{*}{ Setor } & Bens industriais & 120 & $15,48 \%$ & $15,48 \%$ \\
\hline & Consumo cíclico & 200 & $25,81 \%$ & $41,29 \%$ \\
\hline & Consumo não cíclico & 70 & $9,03 \%$ & $50,32 \%$ \\
\hline & Financeiro e outros & 135 & $17,42 \%$ & $67,74 \%$ \\
\hline & Materiais básicos & 80 & $10,32 \%$ & $78,06 \%$ \\
\hline & Petróleo, gás e biocombustíveis & 20 & $2,58 \%$ & $80,65 \%$ \\
\hline & Saúde & 30 & $3,87 \%$ & $84,52 \%$ \\
\hline & Tecnologia da informação & 20 & $2,58 \%$ & $87,10 \%$ \\
\hline & Telecomunicações & 5 & $0,65 \%$ & $87,74 \%$ \\
\hline & Utilidade pública & 95 & $12,26 \%$ & $100 \%$ \\
\hline Total & & 775 & $100 \%$ & \\
\hline \multirow{3}{*}{$\begin{array}{l}\text { Governança } \\
\text { corporativa }\end{array}$} & Nível 1 & 115 & $14,84 \%$ & $14,84 \%$ \\
\hline & Nível 2 & 90 & $11,61 \%$ & $26,45 \%$ \\
\hline & Novo Mercado & 570 & $73,55 \%$ & $100 \%$ \\
\hline Total & & 775 & $100 \%$ & \\
\hline \multirow[t]{2}{*}{ ADR } & Não emite ações no exterior & 410 & $52,90 \%$ & $52,90 \%$ \\
\hline & Emite ações no exterior & 365 & $47,10 \%$ & $100 \%$ \\
\hline Total & & 775 & $100 \%$ & \\
\hline
\end{tabular}

Fonte: elaborado pelos autores. 
No que tange aos setores, "consumo cíclico" e "financeiro e outros" foram os mais representativos. Quanto ao nível de governança corporativa, grande parte das empresas da amostra são listadas no Novo Mercado e suas ações estão divididas quase equitativamente entre emissões ou não de títulos no mercado americano.

\subsection{Apresentação e análise dos resultados}

Para atender aos requisitos apresentados por Fávero et al. (2014), quanto à regressão linear múltipla, testou-se a correlação dos dados e constatou-se a não existência de forte correlação entre eles. A Tabela 5 apresenta os resultados sem as variáveis de controle.

Tabela 5

Resultado da regressão sem variáveis de controle

\begin{tabular}{c|cccccc}
\hline pa_sqt & Coef. & Std. Err. & T & P>t & [95\% Conf. Interval] \\
\hline Val_a & 0 & 0 & 5,30 & 0 & 0 & 0 \\
Vatpro & 0,02 & 0,01 & 1,72 & 0,09 & -0 & 0,05 \\
_cons & 0,94 & 0,01 & 110,05 & 0,00 & 0,92 & 0,96 \\
\hline
\end{tabular}

$\mathrm{F}(2,711)=16,86$

$\mathrm{R}$ quadrado $=0,02$

Prob $>\mathrm{F}=0$

Nota. Pa_sqt: Preço da ação corrigido pela raíz quadrada; Val_a: Valor Adicionado Líquido para distribuição por ação; Vatpro: Proporção do valor adicionado distribuído para capital próprio. Fonte: elaborado pelos autores.

Ao analisar isoladamente o efeito das variáveis da DVA e sua relação com o preço da ação, conforme descrito na Tabela 5 , o teste $F$ evidenciou uma estatística de 16,86. Com esse resultado, permite-se rejeitar a hipótese nula de que todos os parâmetros sejam estatisticamente iguais à zero, ou seja, de que existe pelo menos um coeficiente das variáveis explicativas que é estatisticamente significante a 5\%. O teste $t$ demonstrou que apenas o valor adicionado líquido para distribuição por ação (val_a) mostrou-se significante ao nível de 5\%, porém com baixo poder explicativo da variável $\mathrm{pa}$. Os resultados indicam que o total de riqueza líquida obtida pela empresa pode explicar o seu desempenho no mercado de capitais, sinalizando que as informações contábeis são relevantes para as decisões dos usuários.

Com a finalidade de encontrar uma explicação melhor para a variação do preço das ações e certificar-se que mesmo na presença de outras variáveis, o valor adicionado por ação realmente é significativo para o preço das ações, foram adicionadas outras variáveis. Para dar mais consistência à pesquisa, foram acrescentadas ao modelo as variáveis representativas da DVA, que são extraídas da literatura e se mostravam relacionadas à relevância informacional - ou seja, apontadas como variáveis que podem influenciar a decisão do investidor em termos monetários. Assim, foi possível verificar se o conteúdo informacional contido influencia ou não o preço das ações das empresas objeto de estudo, controlados outros fatores. O resultado do teste de regressão do modelo completo pode ser visualizado na Tabela 6.

Tabela 6

Resultado da regressão com variáveis de controle

\begin{tabular}{r|cccccc}
\hline Pa_sqt & Coef. & $\begin{array}{c}\text { Robust Std. } \\
\text { Err. }\end{array}$ & $\mathbf{t}$ & P>t & [95\% Conf.Interval] \\
\hline La & 0 & 0 & 5,81 & 0 & 0 & 0,01 \\
Val_a & 0 & 0 & 1,96 & 0,05 & 0 & 0 \\
Vpa & -0 & 0 & $-4,27$ & 0 & -0 & -0 \\
Vatpro & 0,01 & 0,01 & 1,23 & 0,22 & $-0,01$ & 0,04 \\
End & -0 & 0 & $-1,63$ & 0,10 & $-0,01$ & 0 \\
Atl & 0,01 & 0,01 & 1,98 & 0,05 & 0 & 0,03
\end{tabular}


Análise da Value Relevance da demonstração do valor adicionado nos níveis diferenciados de governança corporativa da BM\&FBOVESPA

\begin{tabular}{|c|c|c|c|c|c|c|c|c|}
\hline 2 & -0 & 0,02 & $-0,11$ & 0,91 & $-0,05$ & & 0,04 & \\
\hline 3 & 0,05 & 0,03 & 1,81 & 0,07 & -0 & & 0,10 & \\
\hline 4 & 0,02 & 0,02 & 0,93 & 0,35 & $-0,02$ & & 0,06 & \\
\hline 5 & 0,01 & 0,03 & 0,30 & 0,76 & $-0,05$ & & 0,07 & \\
\hline 6 & 0,03 & 0,04 & 0,78 & 0,43 & $-0,04$ & & 0,10 & \\
\hline 7 & 0,07 & 0,03 & 2,16 & 0,03 & 0,01 & & 0,14 & \\
\hline 8 & 0 & 0,03 & 0,02 & 0,98 & $-0,07$ & & 0,07 & \\
\hline 9 & $-0,01$ & 0,09 & $-0,07$ & 0,94 & $-0,18$ & & 0,16 & \\
\hline 10 & 0,06 & 0,03 & 2,19 & 0,03 & 0,01 & & 0,11 & \\
\hline \multicolumn{9}{|l|}{ Gcorp } \\
\hline 2 & 0,04 & 0,03 & 1,13 & 0,26 & & $-0,03$ & & 0,10 \\
\hline 3 & 0,06 & 0,02 & 2,58 & 0,01 & & 0,01 & & 0,11 \\
\hline \multicolumn{9}{|l|}{ Ano } \\
\hline 2012 & 0,20 & 0,02 & 10,10 & 0 & & 0,16 & & 0,24 \\
\hline 2013 & 0,02 & 0,02 & 1,48 & 0,14 & & $-0,01$ & & 0,06 \\
\hline 2014 & $-0,01$ & 0,02 & $-0,75$ & 0,45 & & $-0,05$ & & 0,02 \\
\hline 2015 & $-0,06$ & 0,02 & $-2,84$ & 0,01 & & $-0,10$ & & $-0,02$ \\
\hline Adr & $-0,01$ & 0,01 & $-0,85$ & 0,40 & & $-0,04$ & & 0,02 \\
\hline _cons & 0,68 & 0,10 & 6,54 & 0,00 & & 0,48 & & 0,88 \\
\hline
\end{tabular}

$\mathrm{F}(22,691)=16,31$

Shapiro-Francia $($ Prob $>z)=0,67$

Prob $>\mathrm{F}=0,00$

VIF (variance inflation fator $)=1,67$

$\mathrm{R}$ quadrado $=0,3437$

Nota. Pa_sqt: Preço da ação corrigido pelo método da raiz quadrada; La: Lucro por ação; Val_a: Valor Adicionado Líquido para distribuição por ação; VPA: Valor patrimonial por ação; Vatpro: Proporção do valor adicionado distribuído para capital próprio; End: Endividamento; At: Ativo total corrigido pelo logaritmo neperino; Set: Setor; Gcorp: Governança Corporativa. Fonte: elaborado pelos autores.

Conforme apresentado na Tabela 6, ao acrescentar as demais variáveis, o teste $\mathrm{F}$ resultou em uma estatística de 16,31 que, em uma distribuição $\mathrm{F}$, retornou um p-valor inferior a 0 . Esse resultado conduz à rejeição da hipótese nula, assim como no teste anterior.

Dentre as variáveis quantitativas, apenas as de proporção do valor adicionado distribuído em forma de remuneração do capital próprio (vatpro) e endividamento (end) não se mostraram estatisticamente significantes a 5\%, com um p-valor superior a 0,05 - ou seja, as hipóteses 4 e 5 foram rejeitadas.

Em relação às variáveis qualitativas (i. gov, i.setor, i.ano adr), os resultados dos testes $t$ permitiram concluir, considerando o setor 1, a governança corporativa nível 1 e o ano de 2011 como grupos de referência, que há diferenças entre os setores, os anos e os níveis de governança corporativa para o comportamento da variável preço da ação. Por outro lado, para a dummy adr, pode-se concluir que não há diferença entre as empresas que emitem ações nos Estados Unidos e as que não emitem, para o comportamento da variável preço da ação.

Com base no resultado da regressão sem as variáveis de controle, constatou-se que apenas o valor adicionado líquido para distribuição apresentou significância ao nível de 5\%, confirmando os achados de Machado et al. (2015), que concluíram que a riqueza criada por ação representa melhor capacidade de explicar o retorno das ações.

A cada unidade monetária (Tabela 6) em que houver alteração do lucro por ações, o preço da ação também sofrerá alteração. Considerando a significância no lucro por ação em relação às demais variáveis, o resultado corrobora os achados de Scherer (2006), Machado et al. (2015), e Stanzani et al. (2016), ao constatarem a relevância do lucro em influenciar o retorno das ações.

Nota-se que a variável valor adicionado também se mostrou significativa, porém o aumento acrescido no preço da ação com o aumento de uma unidade monetária de valor 
adicionado por ação parece pouco significativa. Barros et al. (2003) constataram que empresas pertencentes a níveis diferenciados de governança corporativa tendem a apresentar melhores práticas e, assim como os achados deste estudo, encontraram relevância na variável valor adicionado líquido.

Quanto à variável valor patrimonial por ação (vpa), observou-se significância, porém, a cada alteração monetária no vpa reduz-se o preço das ações, corroborando alguns estudos que, ao analisarem o impacto do patrimônio líquido, evidenciaram sua relevância em explicar o retorno das ações (Barros et al., 2013; Machado et al., 2015; Scherer, 2006).

De forma similar a estudos internacionais que vêm mostrando a importância de melhores práticas de proteção aos investidores, as variáveis dummies comprovaram que se a empresa estiver listada no nível de governança Novo Mercado, o preço da ação terá uma variação positiva, em consonância com os achados de Habib e Azim (2008) e Lopes (2009).

Ao analisar os resultados para o período de 2011 a 2015, verifica-se que o ano de 2012 destacou-se entre os demais pelo acréscimo no preço das ações. Em 2012, a economia encontrava-se em um cenário de maior liquidez global e maior confiança dos investidores no que tange a melhores práticas voltadas à transparência, que atraíram, consequentemente, mais investidores.

O ano de 2015 também apresentou significância estaticamente, porém, ocorreu uma queda no preço das ações, tendo sido um ano marcado pela desaceleração da economia chinesa e elevadas quedas na bolsa brasileira (Barbosa, Severiano, \& Malan, 2015).

Outro ponto importante que se destaca nos resultados é o impacto do setor no preço das ações. Verificou-se que, se a empresa pertence ao setor de saúde ou ao setor de utilidade pública, há maior possibilidade de haver impacto no preço das ações em relação às empresas pertencentes aos demais setores. O fato de a empresa ser do setor de saúde proporciona aumento no preço das ações, e se for do setor de utilidade pública, isso proporcionará um aumento no preço das ações.

Tabela 7

Resumo dos resultados por meio da confirmação das hipóteses

\begin{tabular}{cccc}
\hline Hipótese & Variável & Sinal esperado & Sinal encontrado \\
\hline H1 & La & + & + \\
H2 & Val_a & + & + \\
H3 & Vpa & + & - \\
H4 & Vatpro & + & n.s. \\
H5 & End & - & n.s. \\
H6 & Atl & + & + \\
H7 & Set & + & + \\
H8 & Gcorp & + & + \\
H9 & Adr & + & n.s.
\end{tabular}

Nota. La: Lucro por ação; Val_a: Valor Adicionado Líquido para distribuição por ação; Vpa: Valor patrimonial por ação; Vatpro: Proporção do valor adicionado distribuído para capital próprio; End: Endividamento; Atl: Ativo total corrigido pelo logaritmo neperino; Set: Setor; Gcorp: Governança Corporativa. Fonte: elaborado pelos autores.

Constatou-se (Tabela 7) a aceitação das hipóteses 1, 2, 3 e 6 ao evidenciar que o lucro por ação, o valor adicionado por ação, o valor patrimonial por ação e o tamanho da empresa apresentam relevância para o preço das ações, assim como as variáveis de controle setor, índice de governança corporativa e período de análise. A demonstração do valor adicionado por ação, objeto principal do estudo, apresentou relevância para o mercado, apesar do baixo poder de explicação do retorno acionário. Os resultados indicam a relevância da informação em termos da riqueza criada como um todo pela empresa, bem como foi constatada a relevância do lucro por ação e do ativo total das empresas, o que denota que as informações contábeis exercem value relevance, isto é, indicam efeito sobre as decisões dos usuários. 


\section{CONSIDERAÇÕES FINAIS}

Dada a obrigatoriedade da DVA no Brasil, este estudo buscou averiguar a relevância do conteúdo informacional dela no mercado acionário brasileiro, visto que os usuários da informação contábil e os investidores estão cada vez mais preocupados em prover informações com mais transparência e confiabilidade. Esta pesquisa investigou, no período temporal de cinco anos, a relevância dessa demonstração nos níveis diferenciados de governança corporativa (IGCX).

As evidências encontradas confirmaram a relevância da DVA no mercado acionário, porém com baixo poder explicativo. Quando as variáveis de controle foram adicionadas na regressão, notou-se que o lucro por ação se mostrou mais significante em termos de poder explicativo das variações no retorno acionário.

Dentre as hipóteses de pesquisa, foram rejeitadas as que indicavam haver influência do capital próprio distribuído aos acionistas, e o endividamento com as variações no preço da ação também não justifica essas variações. Os resultados apontam para a preocupação dos investidores com a riqueza gerada como um todo, e não apenas com sua distribuição e retenção dos lucros pela empresa. Contudo, observa-se que os investidores não estão preocupados, supostamente, sobre como a riqueza é distribuída, mas estão, sobretudo, interessados em saber o quanto de riqueza foi gerada (valor adicionado a distribuir) e o valor do lucro obtido (lucro líquido, que é um dos principais determinantes dos dividendos), bem como o tamanho da empresa, ou seja, a capacidade da empresa em gerar e manter ativos.

Os resultados encontrados estão em consonância não só com a literatura nacional, como também com a internacional. Quando analisadas as variáveis qualitativas, constatou-se que empresas pertencentes ao nível Novo Mercado de governança corporativa tendem a influenciar o retorno das ações, como constatou Cahan et al. (2009), os quais apontaram a relevância de variáveis relacionadas ao lucro, associadas à qualidade dos ganhos auferidos pelos investidores, sendo esses ganhos relacionados a sua transparência e proteção.

Considera-se que o objetivo deste estudo foi alcançado, ao constatar que o conteúdo informacional da DVA influencia a decisão dos investidores no mercado de capitais brasileiro. Porém, conforme a literatura sugere, a DVA é uma informação complementar às demais informações contábeis.

Como limitação deste estudo, tem-se a investigação apenas de empresas de um país, sendo importante investigar empresas de mercados distintos para capturar os diferentes aspectos da influência da informação contábil no mercado de capitais. Tomando por base os resultados da pesquisa, sugere-se para estudos futuros, a análise da relevância da DVA de forma mais detalhada para os diferentes setores da economia, dada a escassez de estudos que pudessem justificar a relevância do setor de saúde ou utilidade pública na formação do preço das ações.

\section{REFERÊNCIAS}

Almeida, R. L., \& Coutinho e Silva, A. H. (2014). Demonstração do Valor Adicionado: uma análise de sua comparabilidade após torna-se obrigatória no Brasil. Revista de Contabilidade do Mestrado em Ciências Contábeis da Uerj, 19(1), 95-110.

Arruda, M. P., Garcia, I. A. S., \& Lucena, W. G. L. (2015). A influência do valor adicionado na precificação das ações das companhias abertas brasileiras listadas na BM\&FBovespa. Anais do Congresso USP de Controladoria e Contabilidade, São Paulo, SP, Brasil, 15.

Azevedo, O. R. (2009). Demonstrações do fluxo de caixa e do valor adicionado: método direto e indireto passo a passo ( $2 \mathrm{a}$ ed.). São Paulo: IOB. 
Barros, C. M. E., Catapan, A., Scherer, L. M., \& Isidoro, C. (2013). Relevância do valor adicionado: um estudo empírico em sociedades anônimas abertas brasileiras. Registro Contábil, 4(3), 147-162.

Barbosa, D., Severiano, A., \& Malan, C. (2015). Desaceleração da economia chinesa faz Bovespa cair quase 6\%. Jornal Hoje. Recuperado em 20 março, 2019, de http://g1.globo.com/jornal-hoje/noticia/2015/08/desaceleracao-da-economia-chinesa-fazbovespa-cair-quase- $6 . h$ tml

Britto, W. S. F., Silva, E. B, Diniz, S. M., \& Miranda, A. R. (2005). A Demonstração do Valor Adicionado na cadeia produtiva da manga: estudo de caso na região do vale do São Francisco. Anais do Congresso da Sociedade Brasileira de Economia, Administração e Sociologia Rural, Ribeirão Preto, SP, Brasil, 43.

Cahan, S. F., Emanuel, D., \& Sun, J. (2009). The effect of earnings quality and country-level institutions on the value relevance of earnings. Review of Quantitative Finance and Accounting, 33(4), 371-391.

Cosenza, J. P. (2003). A eficácia informativa da demonstração do valor adicionado. Revista Contabilidade \& Finanças, 14(1), 7-29.

Comitê de Pronunciamentos Contábeis (CPC). (2008). Pronunciamento técnico CPC 09: demonstração do valor adicionado. Recuperado em 20 de março, 2019, de http://static.cpc.aatb.com.br/Documentos/175_CPC_09.pdf

Crippa, M., \& Coelho, A. C. D. (2012). Relevância e conteúdo informacional da demonstração do valor adicionado: evidências para o Brasil. Anais da Associação Nacional de Programas de Pós-Graduação em Ciências Contábeis, Florianópolis, SC, Brasil, 6.

Cunha, J. V. A., Ribeiro, M. S., \& Santos, A. (2005). A demonstração do valor adicionado como instrumento de mensuração da distribuição da riqueza. Revista Contabilidade \& Finanças, 16(37), 7-23.

Fávero, L. P., Belfiore, P., Takamatsu, R. T., \& Suzart, J. (2014). Métodos quantitativos com Stata. Rio de Janeiro: Elsevier.

Fé, A. L. D., Jr. (2013). Mudanças contábeis e reações do mercado na implantação compulsória do IFRS no setor bancário brasileiro. Tese de Mestrado, Faculdade de Economia, Administração e Contabilidade de Ribeirão Preto, Universidade de São Paulo. Ribeirão Preto, SP, Brasil.

Habib, A., \& Azim, I. (2008). Corporate governance and the value-relevance of accounting information: Evidence from Australia. Accounting Research Journal, 21(2), 167-194.

Haller, A., \& Van Staden, C. (2014). The value added statement-an appropriate instrument for Integrated Reporting. Accounting, Auditing \& Accountability Journal, 27(7), 1190-1216.

Klapper, L. F., \& Love, I. (2002). Corporate governance, investor protection, and performance in emerging markets. Journal of corporate Finance, 10(5), 703-728. 
Kroetz, C. E. S., \& Neumann, M. (2008). Responsabilidade social e a demonstração do valor adicionado. Desenvolvimento em Questão, 6(11), 153-178.

Lei n. 11.638, de 28 de dezembro de 2007 (2007). Altera e revoga dispositivos da Lei no 6.404, de 15 de dezembro de 1976, e da Lei $\mathrm{n}^{\circ}$ 6.385, de 7 de dezembro de 1976, e estende às sociedades de grande porte disposições relativas à elaboração e divulgação de demonstrações financeiras. Recuperado em 25 Janeiro, 2017, de http://www.planalto.gov.br/ccivil_03/_ato2007-2010/2007/lei/l11638.htm

Lima, J. B. N. (2010). A relevância da informação contábil e o processo de convergência para as normas IFRS no Brasil. Tese de Doutorado, Faculdade de Economia, Administração e Contabilidade, Universidade de São Paulo. São Paulo, SP, Brasil.

Lopes, A. B. (2009). The relation between firm-especific corporate governance, cross-listing and the informativeness of accouting numbers in Brazil. $\mathrm{PhD}$ Thesis, Manchester Business School, University of Manchester, Manchester, United Kingdom.

Luca, M. M. M., Cunha, J. V. A., Ribeiro, M. S., \& Oliveira, M. C. (2009). Demonstração do valor adicionado: do cálculo da riqueza criada pela empresa ao valor do PIB (2a ed.). São Paulo: Atlas.

Macedo, M. Á. S., Romano, T. D., \& Silva, J. C. Q. (2014). Análise dos determinantes da relevância das informações contábeis no brasil: um estudo com base no lucro líquido (LL) e no patrimônio líquido (PL) para o período de 2010 a 2012. Anais do Congresso Usp de Controladoria e Finanças, São Paulo, 14. Recuperado em 20 de março, 2019, de http://www.congressousp.fipecafi.org/web/artigos142014/276.pdf

Machado, M. A. V., Macedo, M. A. S., \& Machado, M. R. (2015). Análise da relevância do conteúdo informacional da dva no mercado brasileiro de capitais. Revista Contabilidade \& Finanças, 26(67), 57-69.

Malacrida, M. J. C., \& Yamamoto, M. M. (2006). Governança corporativa: nível de evidenciação das informações e sua relação com a volatilidade das ações do Ibovespa. Revista contabilidade e finanças, 17(1), 65-79.

Marques, A. V. C., Santos, C. K. S., \& Lemes, S. (2014). Divulgação dos relatórios contábeis: um estudo da relevância das informações contábeis sobre ativos intangíveis. Anais do Encontro da Associação Nacional de Pós-Graduação e Pesquisa em Administração. Rio de Janeiro, RJ, Brasil, 38.

Martins, V. G., Machado, M. A. V., \& Callado, A. L. C. (2014). Análise da aditividade de value relevance da DDF e da DVA ao conjunto de demonstrações contábeis: evidências de empresas do mercado de capitais brasileiro. Contabilidade, Gestão e Governança, 17(1), 75-94.

Mook, L. I. (2007). Social and environmental accounting: the expanded value added statement. Doctoral dissertation, University of Toronto. Toronto, Canada.

Oliveira, I. A. F., \& Coelho, A. C. D. (2014). Impacto da divulgação obrigatória da DVA: evidência em indicadores financeiros. Revista Evidenciação Contábil \& Finanças, 2(3), 41-55. 
Oshiro, R. (2003). Demonstração do Valor Adicionado. In J. C. Marion, \& A. C. R. Reis (Coords.). Mudanças nas demonstrações contábeis (pp.70-80). São Paulo: Saraiva.

Rezende, A. J., Batistella, F. D., Dalmácio, F. Z., \& Brito, G. A. (2008). A relevância da informação contábil no mercado de ações brasileiro: uma análise informação societária e informação corrigida. Anais do Encontro da Associação Nacional de Pós-Graduação e Pesquisa em Administração. Rio de Janeiro, RJ, Brasil, 32.

Rodrigues, J. M., Elias, W. G., \& Campos, E. S. (2014). Relevância da informação contábil: uma análise dos efeitos da contabilização dos gastos com pesquisa e desenvolvimento com a aplicação da Lei 11.638/07 no mercado brasileiro. Anais do Congresso USP de Controladoria e Finanças. São Paulo, SP, Brasil, 14.

Scherer, L. M. (2006). Valor adicionado: análise empírica de sua relevância para as companhias abertas que publicam a demonstração do valor adicionado. Tese de Doutorado, Universidade de São Paulo, São Paulo, SP, Brasil.

Stanzani, L. M. L., Fregonesi, M. S. F. A., \& Nakao, S. H. (2016). Estudo da relevância do valor adicionado contábil. Anais da Associação Nacional de Programas de Pós-Graduação em Ciências Contábeis. Ribeirão Preto, SP, Brasil, 10.

Van Staden, C. J. (2000). The value added statement: bastion of social reporting or dinosaur of financial reporting? Working and Discussion Papers, Massey University, University of New Zealand. Retrieved from http://mro.massey.ac.nz/handle/10179/2543

Yogesha, B. S., \& Mahadevappa, B. (2014). Analysis of value added ratios of indian oil corporation ltd. IOSR Journal of Humanities and Social Science (IOSR-JHSS), 19(1), 1825. 